Supplement of Clim. Past, 16, 161-181, 2020

https://doi.org/10.5194/cp-16-161-2020-supplement

(c) Author(s) 2020. This work is distributed under

the Creative Commons Attribution 4.0 License.

(c) (1)

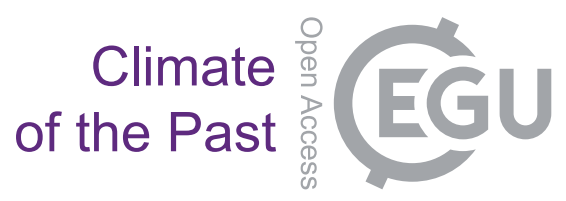

Supplement of

\title{
The effect of mountain uplift on eastern boundary currents and upwelling systems
}

\section{Gerlinde Jung and Matthias Prange}

Correspondence to: Gerlinde Jung (gjung.sc@gmail.com)

The copyright of individual parts of the supplement might differ from the CC BY 4.0 License. 
1) Evaluation of upwelling velocities - control run (CTRL)
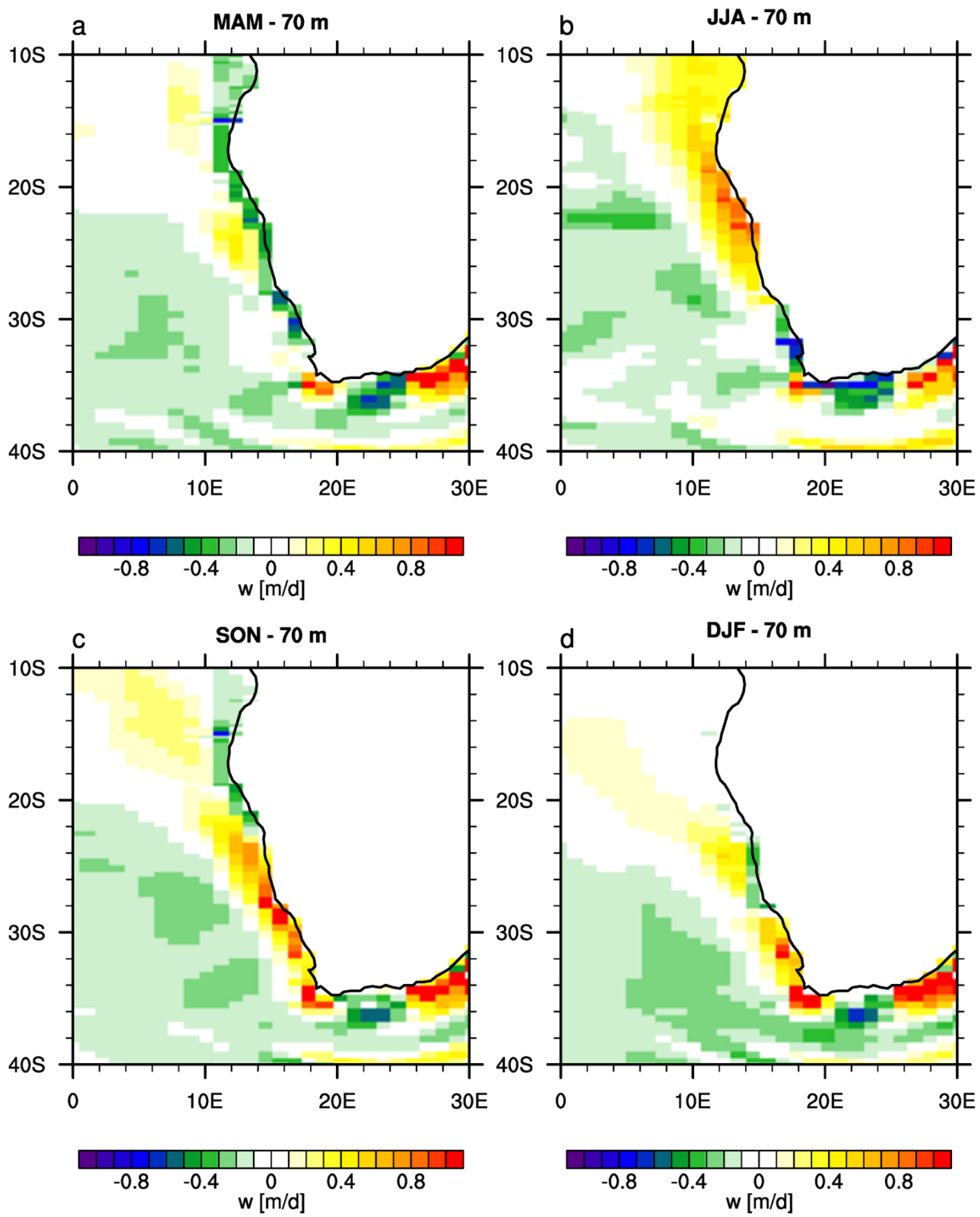

S1: Seasonal mean vertical velocity $\left[\mathrm{m} \mathrm{d}^{-1}\right]$ at a depth of $70 \mathrm{~m}$ in the control run (CTRL) for MAM (a), JJA (b), SON (c), DJF (d). Positive (negative) values denote upward (downward) motion. 

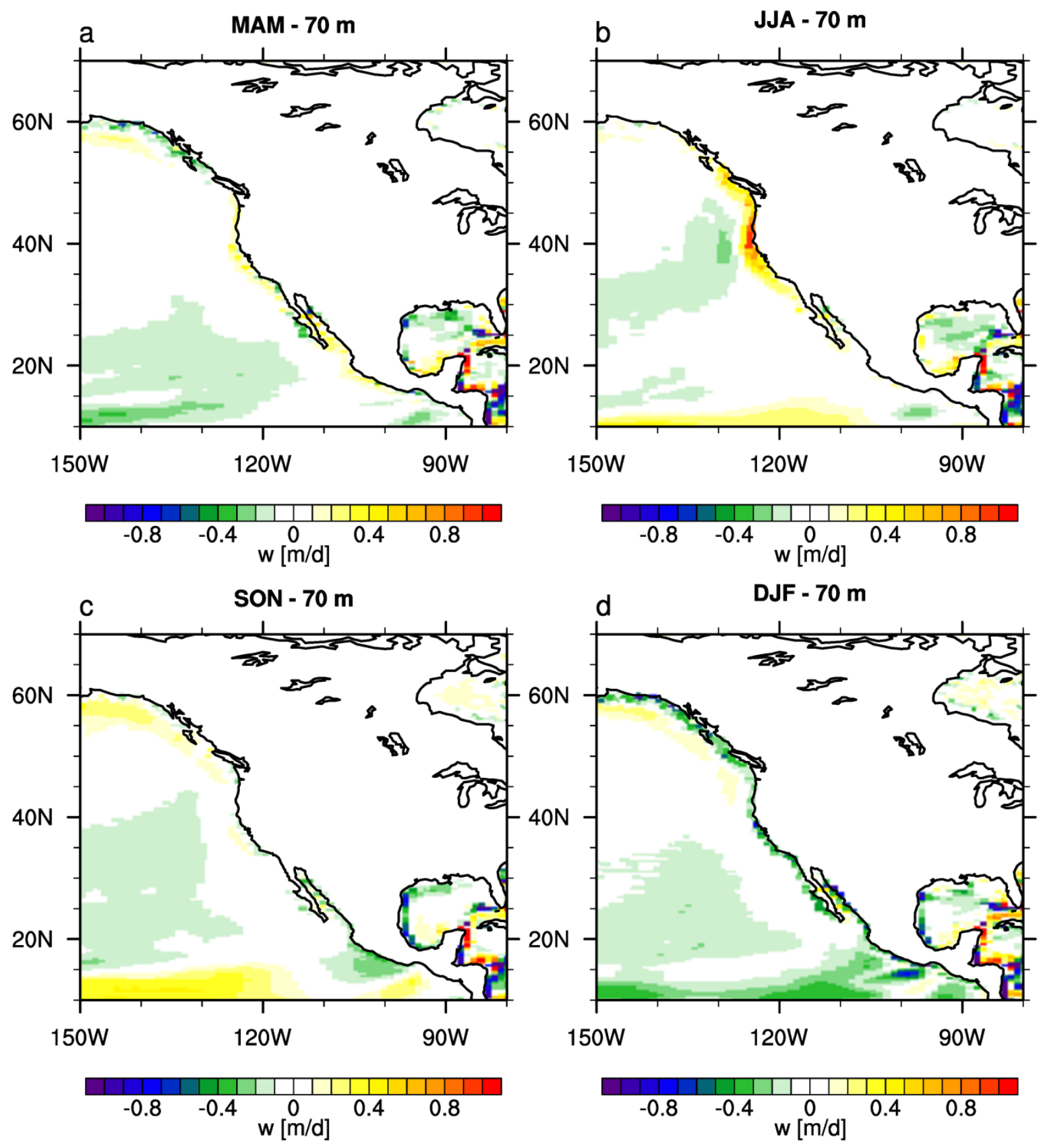

S2: Seasonal mean vertical velocity $\left[\mathrm{m} \mathrm{d}^{-1}\right]$ at a depth of $70 \mathrm{~m}$ in the control run (CTRL) for MAM (a), JJA (b), SON (c), DJF (d). Positive (negative) values denote upward (downward) motion. 

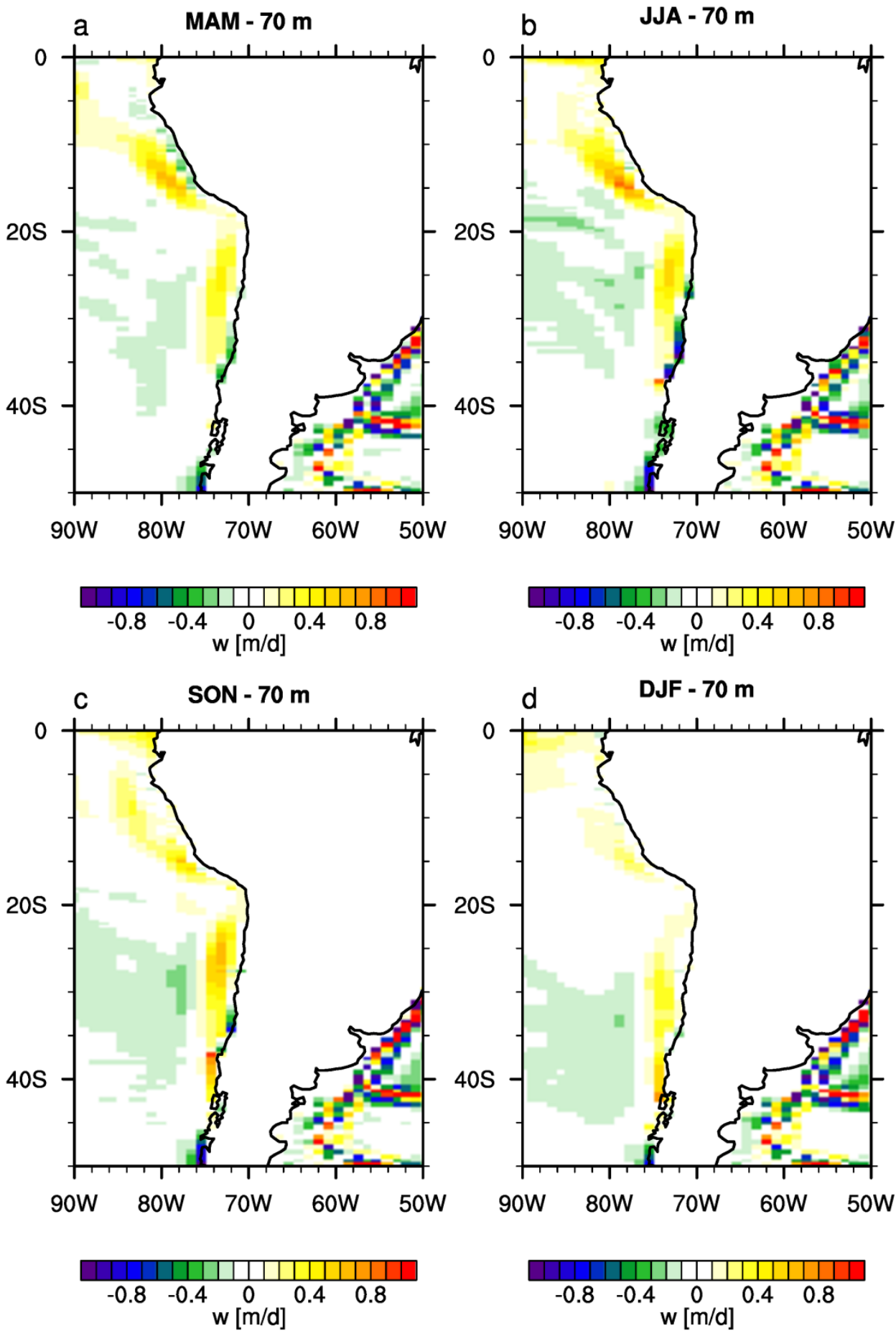

S3: Seasonal mean vertical velocity $\left[\mathrm{m} \mathrm{d}^{-1}\right]$ at a depth of $70 \mathrm{~m}$ in the control run (CTRL) for MAM (a), JJA (b), SON (c), DJF (d). Positive (negative) values denote upward (downward) motion. 
2) Evaluation of upwelling velocities - Carton-Giese SODA 2.2.4 reanalysis
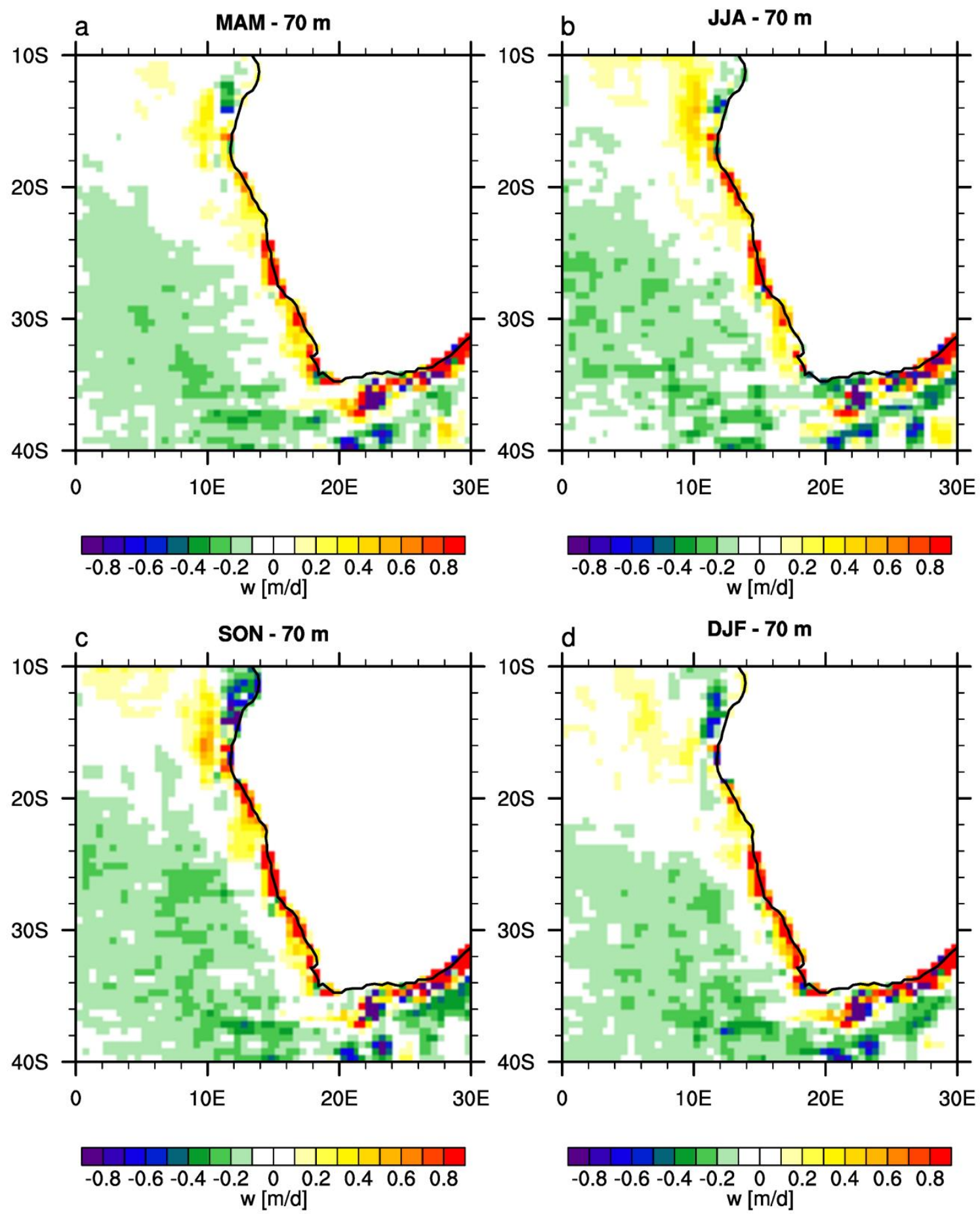

S4: 30-year seasonal averages (1979-2008) of vertical velocity $\left[\mathrm{m} \mathrm{d}^{-1}\right]$ at a depth of $70 \mathrm{~m}$ from Carton-Giese SODA 2.2.4 reanalysis for MAM (a), JJA (b), SON (c), DJF (d). Positive (negative) values denote upward (downward) motion. 

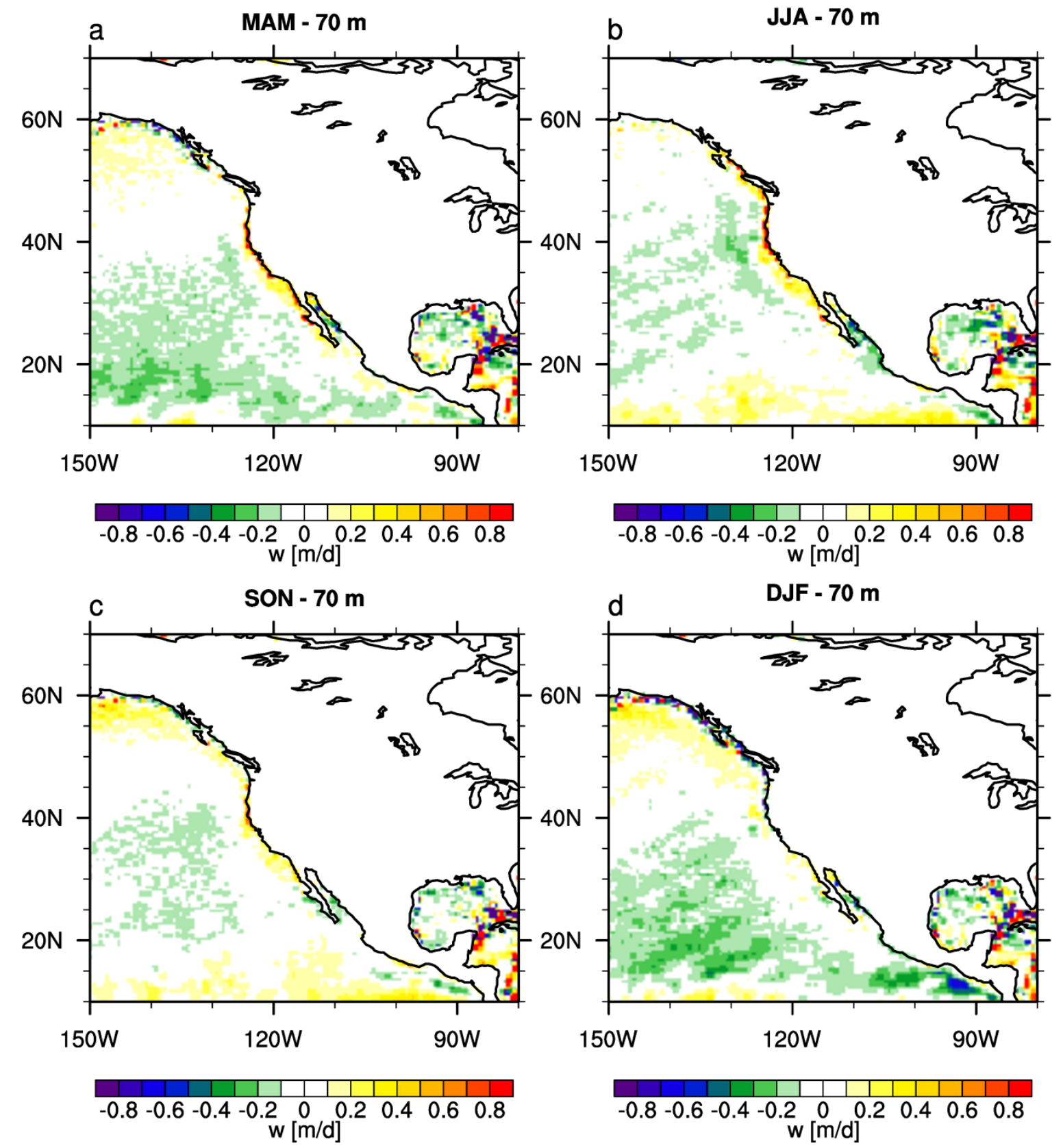

S5: 30-year seasonal averages (1979-2008) of vertical velocity $\left[\mathrm{m} \mathrm{d}^{-1}\right]$ at a depth of $70 \mathrm{~m}$ from Carton-Giese SODA 2.2.4 reanalysis for MAM (a), JJA (b), SON (c), DJF (d). Positive (negative) values denote upward (downward) motion. 

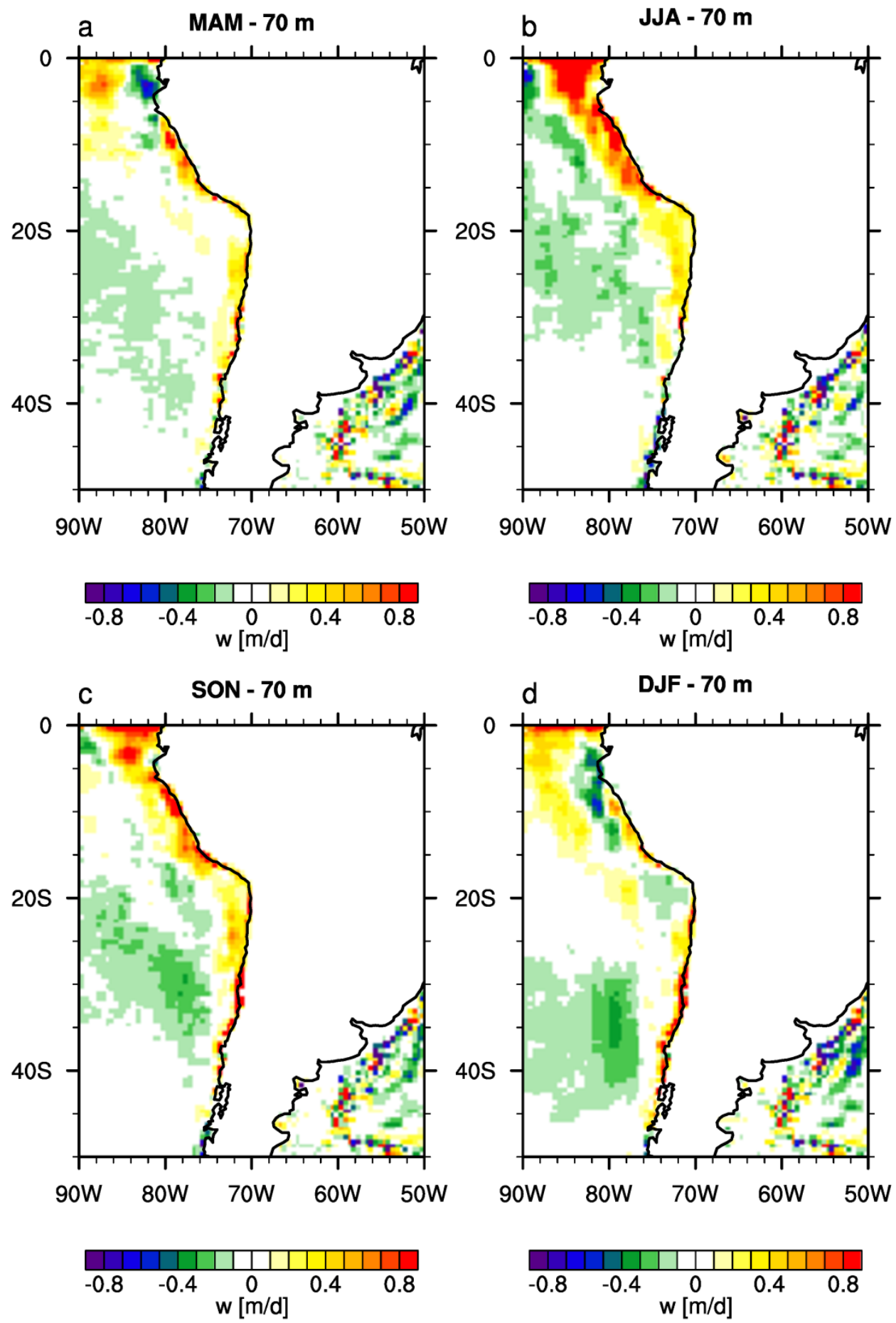

S6: 30-year seasonal averages (1979-2008) of $\mathrm{v}$ ertical velocity $\left[\mathrm{m} \mathrm{d}^{-1}\right]$ at a depth of $70 \mathrm{~m}$ from Carton-Giese SODA 2.2.4 reanalysis for MAM (a), JJA (b), SON (c), DJF (d). Positive (negative) values denote upward (downward) motion. 


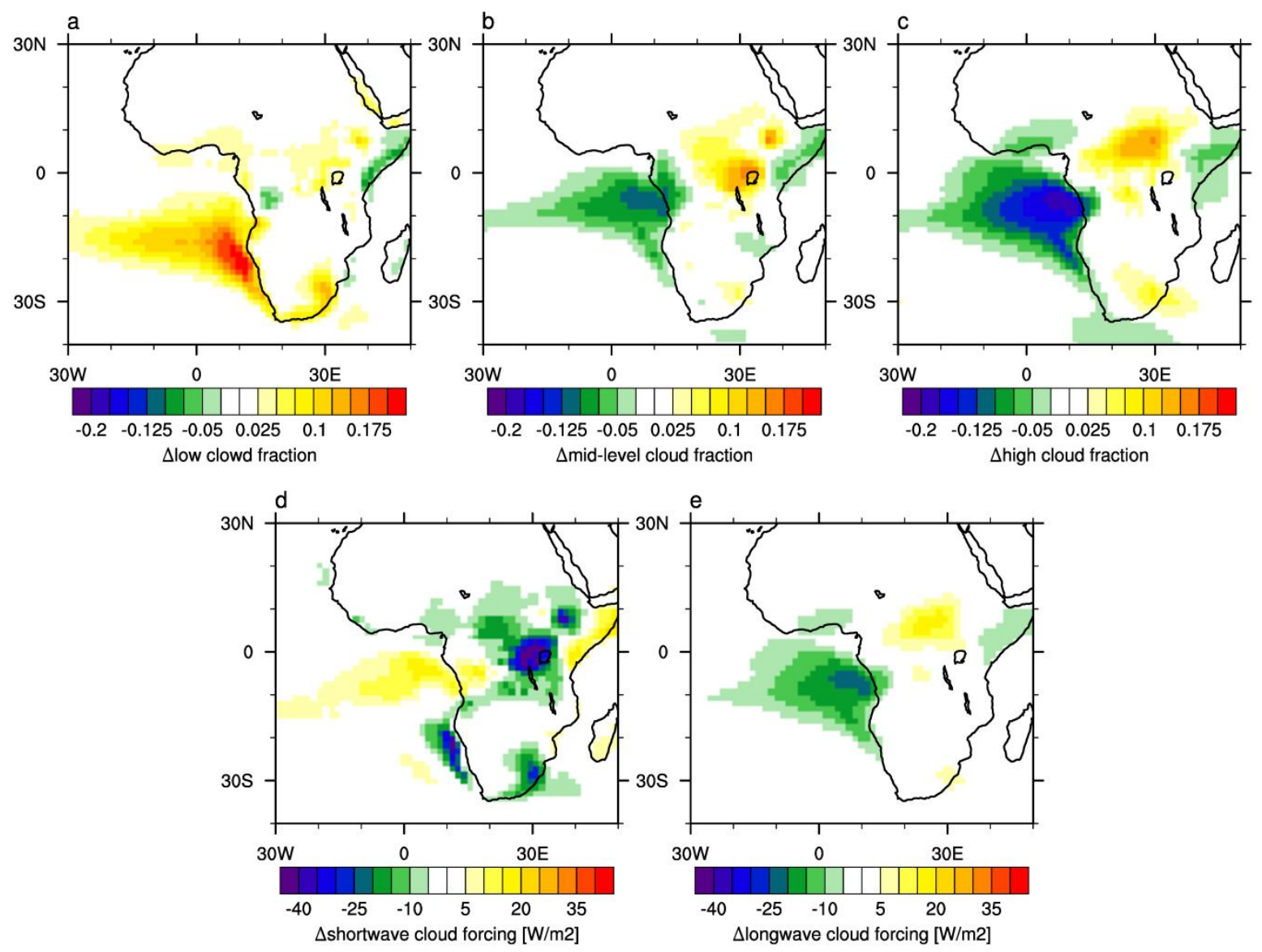

S7: Annual mean responses in low (a), mid-level (b) and high (c) cloud fraction, and in shortwave (d) and longwave (e) cloud forcing [W/m²] to African mountain uplift (CTRL - AF). 

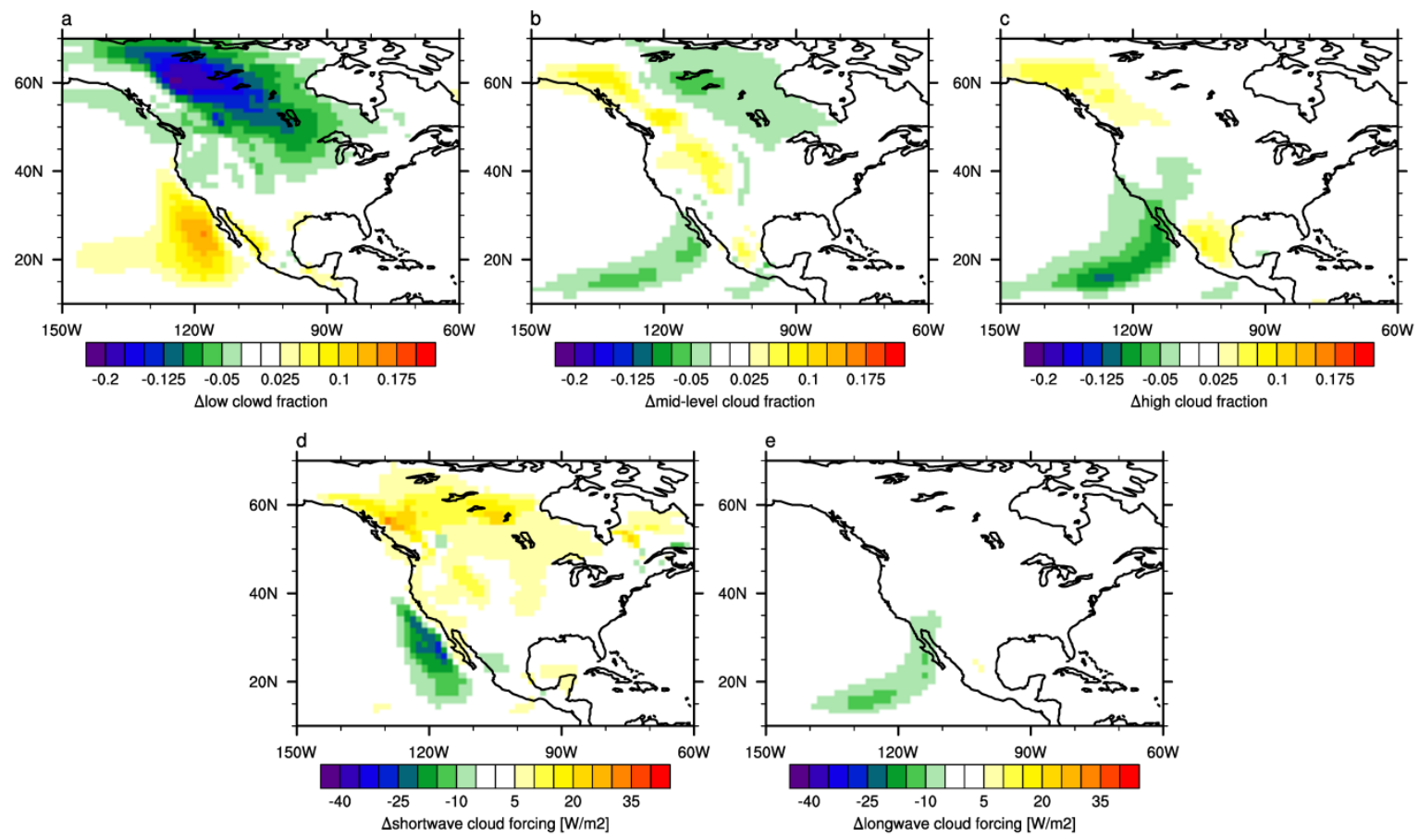

S8: Annual mean responses in low (a), mid-level (b) and high (c) cloud fraction, and in shortwave (d) and longwave (e) cloud forcing $\left[\mathrm{W} / \mathrm{m}^{2}\right]$ to North American mountain uplift (CTRL - NA). 

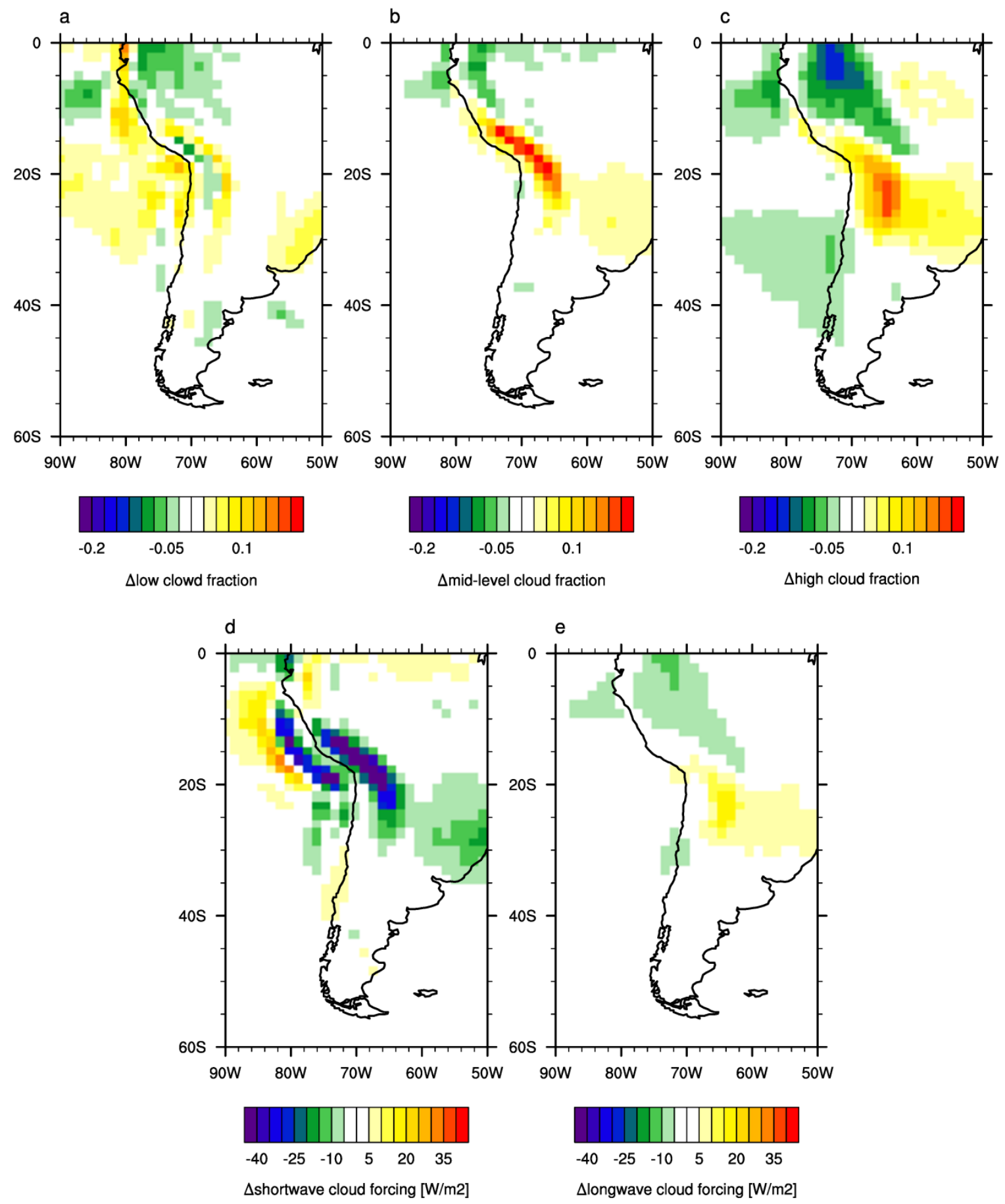

S9: Annual mean responses in low (a), mid-level (b) and high (c) cloud fraction, and in shortwave (d) and longwave (e) cloud forcing [W/m²] to Andean uplift (CTRL - AND). 